\title{
NUEVOS PROYECTOS DE PERIODISTAS EMPRENDEDORES EN EL ESCENARIO HIPERLOCAL; EL CASO DE LA PROVINCIA DE CASTELLÓN
}

\author{
New projects from enterprising journalists in the \\ hyperlocal scene: The case of the \\ Castellón province, Spain
}

\section{Ramón-Serafín Pardo-Baldeón}

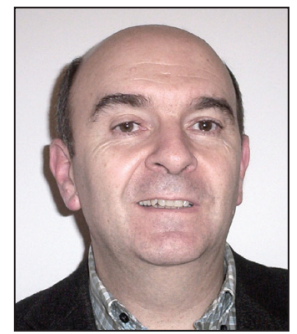

Ramón-Serafín Pardo-Baldeón es profesor asociado de periodismo de la Universitat Jaume I de Castellón por la que es doctor. Licenciado por la Universidad Complutense de Madrid, compagina la tarea docente y de investigación con la de director de comunicación del Colegio de Médicos de Castellón. Vocal de Formación y Nuevas Tecnologías de la Asociación de Periodistas de Castellón. Ha trabajado en El comercio (Gijón), La nueva España (Oviedo), Levante-EMV (Comunitat Valenciana), Antena 3 Radio y Radio Asturias-SER.

htpp://orcid.org/0000-0002-8530-0306

Universitat Jaume I Av. de Vicent Sos Baynat, s/n. 12071 Castelló de la Plana, España pardor@uji.es

\section{Resumen}

La crisis general de las empresas de comunicación afecta también a los periodistas de Castellón, y más tras el cierre de la Radio Televisión Valenciana (RTVV) en noviembre de 2013. Por ello, algunos han optado por crear sus medios digitales, que compiten por un mercado publicitario muy fraccionado. Internet les permite autoemplearse y crear sus diarios aprovechando que el periodismo local es un nicho de trabajo. Se analizan los modelos de negocio de los proyectos periodísticos surgidos en Castellón entre 2008 y 2015, para conocer su evolución y tendencias. Los resultados revelan dos características de este tipo de medios: la falta de un plan de empresa, y la dependencia de las administraciones a la hora de incluir contenidos. Ambos aspectos pueden condicionar el desarrollo futuro de este modelo.

\section{Palabras clave}

Prensa; Periodismo local; Periodismo emprendedor; Nuevos medios; Prensa digital; Diarios.

\section{Abstract}

The communication companies' general crisis affects journalists all over the world, and the ones working in the Spanish province of Castellon are not an exception, specially after the closing down of the regional corporation Valencian Radio Television (RTVV) where many of them were employed. To survive, they chose to create their own digital media, competing for a very fragmented advertising market in the local journalism niche. In this paper, the journalistic projects that emerged in Castellón between 2008 and 2015 are analyzed. We describe their business models and their situation. The results reveal two main characteristics of this type of media: lack of a business plan and dependence on public administration content. Both aspects can determine the future development of these ventures.

\section{Keywords}

Newspapers; Local journalism; Entrepreneurial journalism; New media; Digital media; Newspapers.

Pardo-Baldeón, Ramón-Serafín (2016). “Nuevos proyectos de periodistas emprendedores en el escenario hiperlocal: el caso de la provincia de Castellón”. El profesional de la información, v. 25, n. 3, pp. 423-430.

\section{http://dx.doi.org/10.3145/epi.2016.may.12}




\section{Introducción}

La industria periodística está en proceso de reconversión en medio de una grave crisis que no es sólo consecuencia de la económica que afecta al mundo desde 2007, sino que lleva añadida la de identidad de la profesión y la de modelo de negocio. Larrañaga-Rubio (2009) habla de una doble crisis al aunar la estructural, de tipo microeconómico, que lastra al sector desde los 90, con otra coyuntural fuertemente vinculada a la recesión económica mundial. Esto ha ocasionado un importante descenso de la inversión publicitaria en los medios y con ello la caída de los ingresos-beneficios de las empresas editoras de diarios (Casero-Ripollés; IzquierdoCastillo, 2013).

La crisis económica ha tenido efectos demoledores sobre la industria de la comunicación en general (Curran, 2010), y del periodismo en particular. Los datos del Observatorio de la Asociación de la Prensa de Madrid (APM) de seguimiento de la crisis en los medios españoles confirman que entre 2008 y 2014 se han destruido 11.954 puestos de trabajo, de los cuales 2.465 fueron en 2014, 306 menos que en 2013 cuando se quedaron en paro 2.771 profesionales. Más de la mitad del empleo destruido en 2014 lo generó el despido de 1.600 trabajadores de Radio Televisión Valenciana, tras su cierre por el Consell de la Generalitat Valenciana. Según la Asociación de Periodistas de Castellón (APC), entre 2008 y 2014 perdieron su empleo 48 de los 144 profesionales registrados, el $32 \%$, el doble de la media nacional según la $A P M$. Aferrarse al emprendimiento y al periodismo local como fórmula para salir de la crisis que les dejó sin trabajo fue una de las soluciones para estos periodistas. Esto se refleja en el Informe anual de la profesión periodística 2014 de la $A P M$, que registra 454 cibermedios consolidados, de los que un $40 \%$ son anteriores a 2011. En este contexto, surge la figura del periodista emprendedor (Casero-Ripollés; CullellMarch, 2013).

Los nuevos proyectos encuentran en internet la plataforma para desarrollarse, porque les abre vías para renovar el modelo de negocio, aunque sea en un entorno de reconversión. Casero-Ripollés (2012a), señala que en España el 58\% de los jóvenes de entre 16 y 24 años leen las noticias en internet, lo que confirma el Libro blanco de la prensa diaria 2014 de la patronal de editores de diarios, $A E D E$, al apuntar que el $68,4 \%$ de los lectores de prensa digital tienen menos de 44 años.

En este escenario el periodismo hiperlocal se convierte en un nicho de negocio para los periodistas en paro que apuestan por el emprendimiento. De ahí el interés por conocer el modelo y las características de los proyectos emprendedores en el contexto de una provincia de tipo medio como Castellón, con 579.906 habitantes en 2015, según el Instituto Nacional de Estadística (INE).

Algunos de los periodistas en paro en Castellón apostaron por crear sus propias empresas con unas plantillas casi unipersonales, apoyándose en la figura laboral de los colaboradores, y con unos presupuestos de supervivencia, aprovechando al máximo las ventajas que las tecnologías digitales y la Red les ofrecían para abaratar costes. Ese emprendimiento no es nuevo, ya que hay precedentes estudiados geográficamente por Salaverría et al. (2004) en Catalunya; Vizcaíno-Laorga-Gavilán (2006) en Galicia, o López-García (2006) en la Comunitat Valenciana. Sus estudios reflejan el creciente interés que despertaron aquellas aventuras editoriales que hoy siguen profesionales despedidos de los medios tradicionales.

\section{El periodismo hiperlocal se convierte en un nicho de negocio para los periodistas en paro que apuestan por el emprendi- miento}

\section{Diarios digitales como alternativa al paro}

La irrupción de internet en el mundo de la comunicación es considerada por algunos empresarios de la información como uno de los agentes generadores de la crisis. Incluso muchos periodistas vieron a la Red como uno de sus enemigos, como apuntó Luis Palacio en la presentación del Informe anual de la profesión periodística 2014 de la APM . Sin embargo, la Red y la tecnología asociada se han convertido en un aliado imprescindible para reconducir su futuro profesional. El citado informe afirma que una parte de los periodistas ha dejado de lamentarse y ha optado por una postura proactiva, explorando nuevas fórmulas. Y no sólo los periodistas, sino los editores que pasaron de vivir un período de bonanza (2004 a 2009), con ingresos publicitarios que aseguraban la viabilidad de su modelo de negocio, a tener que sortear la crisis económica que les dejó sin margen de ganancias, a replantearse su actividad y reorganizar los conglomerados empresariales que crearon (Díaz-Nosty, 2013).

Un proceso de cambio de modelo de negocio iniciado hace poco más de un lustro por los periodistas y algunas empresas del sector y que ya auguraban Toffler (1980) y Castells (2001) al señalar internet como herramienta capaz de cambiar profundamente la forma de comunicarse y consumir información, además de agente democratizador de la sociedad y garante del acceso a la información.

Pérez-Bahón y Clemente (2014) destacan que la Red ha permitido a los lectores acceder a las informaciones online de los diarios tradicionales que compiten con los medios nativos digitales. Gil (2002), Rom y Masip (2005) y Salaverría y Negredo (2008) han constatado esos cambios para resaltar los beneficios de internet como plataforma de comunicación capaz de subsumir a los medios tradicionales.

A la hora de plantearse el negocio de la información en la Red se barajan fórmulas como el acceso gratis o de pago. Herbert y Thurman (2007) abordan las opciones de los pure players (nativos digitales) a partir de las primeras aproximaciones a la definición de modelo de negocio, que en España está condicionado por la cultura del gratis total y la depreciación de la información como valor entre los jóvenes (Casero-Ripollés, 2012b).

Autores como Giles (2010), Bruno y Nielsen (2012), y Faustino y Gonçalez (2011) profundizan en el estudio y descripción de los productos y servicios que han de ofertar las nuevas empresas informativas para rentabilizar el consumo 
de noticias en internet. Mientras, Picard (2004) aboga por generar un plus de valor en las informaciones de servicio que se ofrecen a las audiencias. Pese a ello, no está claro cuáles son las claves del éxito y sostenibilidad del negocio en un momento en el que la crisis dificulta la rentabilidad de un medio de comunicación, algo que no fue problema hasta 2007, momento en que la crisis cambió los axiomas clásicos del periodismo (Albarrán, 2010), basados en la publicidad y la venta de ejemplares. Situación que detectan Rosenstiel, Jurkowitz y Ji (2012) al estudiar los modelos de negocio.

García-Santamaría (2014) y Casero-Ripollés (2010) apuntan que el modelo de financiación dominante en los medios digitales españoles es el de los ingresos publicitarios, como en la prensa en papel. Esta es una fórmula que convive con la del acceso limitado a suscriptores (o "muro de pago"). Esa renuncia a otras fórmulas hace que los ingresos por publicidad en internet, tengan un peso importante a la hora de garantizar la viabilidad de los productos y ello, pese a que no superan el $15 \%$ de los ingresos publicitarios de los diarios impresos (Casero-Ripollés; Izquierdo-Castillo, 2013). Por ello, proponen complementar los ingresos obtenidos en los quioscos digitales con los publicitarios. Yuste y Cabrera (2014, pp. 87-132) apuntan otras fuentes de financiación, desde la venta de contenidos o su sindicación, pasando por la publicidad, crowdfunding, suscripciones, cupones descuento, micropagos y apps.

\section{Metodología}

Este artículo presenta un estudio de caso que busca conocer en base a qué criterios empresariales han surgido los diarios online impulsados por periodistas en paro en la provincia de Castellón entre 2008 y julio de 2015. Se aplicó una metodología cualitativa (entrevistas en profundidad y análisis de contenidos), con un cuestionario cerrado enviado por email a los responsables de los 10 medios online creados por periodistas desempleados en el período citado, que respondieron 6 de ellos. Se recurrió a la entrevista a fondo (Balcells, 1994, p. 218) porque facilita al investigador el acceso a datos que pueden pasar desapercibidos al emplear otros métodos y que ofrecen explicaciones sobre los porqués de los fenómenos sociales.

La selección de los medios obedeció a tres características comunes:
- fueron creados por periodistas de Castellón con experiencia laboral en medios tradicionales y que perdieron su trabajo;

- surgieron entre 2008-2015, años en los que la doble crisis económica y profesional se manifestó en España en general, y en Castellón en particular;

- se basan en internet.

Se identificaron varios elementos que los definen, en base a los criterios usados por Manfredi-Sánchez, Rojas-Torrijos y Herranz-de-la-Casa (2015, p. 266):

- propiedad y titularidad del nuevo medio;

- entorno digital y móvil;

- marca personal de los profesionales;

- naturaleza de la propuesta de valor;

- uso de nuevas narrativas periodísticas, entendidas como una característica diferenciadora y que influye en la manera de contar los hechos y explicarlos para captar al lector.

Junto a las entrevistas a fondo, se realizó un análisis de contenido de los 10 medios seleccionados, entre los días 1 y 31 de diciembre de 2014, aplicando los criterios expuestos por De-Fontcuberta (1997) para conocer si la cobertura coincide con el de los medios tradicionales, tal como pluralidad de las fuentes alternativas a las institucionales o si, además de las noticias, optan por géneros más propios como el reportaje o la investigación.

Esta investigación ha tenido en cuenta criterios como la estructura de las plantillas de los diarios, la distribución de las informaciones y su procedencia. Se han revisado 1.437 informaciones aparecidas en las portadas de los 10 ciberdiarios analizados entre el 1 y el 31 de diciembre de 2014 .

\section{Resultados}

\subsection{Diez medios online en seis años}

Al inicio de esta investigación existían en la provincia de Castellón 28 diarios digitales, incluidas las versiones online de cabeceras nacionales o regionales, según datos del Grupo de análisis de los medios digitales valencianos y de la APC. De ellos, 10 se crearon entre 2008 y 2015, un 55,5\% del total. Esos 10 son objeto de esta investigación (si bien en lo que se refiere al cuestionario, respondieron 6), al ser los creados por profesionales en paro y con experiencia previa

Tabla 1. Censo de ciberdiarios creados en Castellón (2008-2014)

\begin{tabular}{|l|l|c|l|}
\hline \multicolumn{1}{|c|}{ Medio } & \multicolumn{1}{|c|}{ Ámbito de cobertura } & Año de creación & \multicolumn{1}{c|}{ web } \\
\hline Castellón información & Provincial & 2012 & http://www.castelloninformacion.com \\
\hline Castellón diario & Provincial & 2011 & http://www.castellondiario.com \\
\hline Comarques nord & Intercomarcal & 2008 & http://comarquesnord.cat \\
\hline Dia a dia & Intercomarcal & 2014 & http://diadia.cat \\
\hline Infomaestrat & Comarcal & 2014 & http://infomaestrat.com \\
\hline La veu de Benicarló & Comarcal & 2011 & http://www.laveudebenicarlo.info \\
\hline Benicarló al día & Comarcal & 2009 & http://www.benicarloaldia.com/index.php \\
\hline La calamanda & Comarcal & 2008 & http://www.lacalamanda.com \\
\hline Infopalancia & Comarcal & 2014 & http://www.infopalancia.com \\
\hline La veu de l'Alcalatén & Comarcal & 2011 & http://www.laveudelalcalaten.blogspot.com \\
\hline
\end{tabular}


Tabla 2. Idioma

\begin{tabular}{|l|l|}
\hline \multicolumn{1}{|c|}{ Medio } & \multicolumn{1}{c|}{ Idioma } \\
\hline Castellón información & Castellano \\
\hline Castellón diario & Castellano \\
\hline Comarques nord & Catalán \\
\hline Dia a dia & Catalán \\
\hline La veu de l'Alcalatén & Valenciano \\
\hline Benicarló al día & Castellano \\
\hline La veu de Benicarló & Catalán \\
\hline Infopalancia & Castellano \\
\hline Infomaestrat & Castellano \\
\hline La calamanda & Catalán \\
\hline
\end{tabular}

en medios tradicionales. Se agruparon por comarcas, lo que permite conocer su campo de actuación y el público al que se dirigen:

- Castellón información y Castellón diario, editados en Castellón ciudad;

- La veu de Benicarló, La calamanda, Benicarló al día e Infomaestrat, en las comarcas del Alt y Baix Maestrat, al norte de la provincia;

- Comarques nord y Dia a dia, en Els Ports, al noroeste;

- La veu de l'Alcalatén, en el interior;

- Infopalancia, en el Alto Palancia, en el límite con Teruel (tabla 1).

En la comarca del Baix Maestrat, que agrupa tres de las poblaciones más importantes de la provincia de Castellón (Vinaròs, Benicarló y Peñíscola) tras la capital y Vila-real, es donde han surgido más proyectos emprendedores en el período estudiado. Las comarcas de Els Ports y del Alt Maes-
Tabla 3. Media de noticias diarias publicadas en portada, noticias procedentes de fuentes oficiales, y total de noticias

\begin{tabular}{|l|c|c|c|}
\hline \multicolumn{1}{|c|}{ Medio } & $\begin{array}{c}\text { Noticias } \\
\text { portada/día }\end{array}$ & $\begin{array}{c}\text { No noticias } \\
\text { oficiales }\end{array}$ & Total \\
\hline Castellón información & 18 & 165 & 550 \\
\hline Castellón diario & 7 & 195 & 217 \\
\hline Comarques nord & $5-6$ & 60 & 170 \\
\hline Infopalancia & $3-4$ & 18 & 108 \\
\hline Dia a dia & 8 & 158 & 176 \\
\hline Infomaestrat & $2-3$ & 65 & 69 \\
\hline La calamanda & 3 & 74 & 93 \\
\hline La veu de l'Alcalatén & $2-3$ & 62 & 62 \\
\hline La veu de Benicarló & 5 & 15 & 15 \\
\hline Benicarló al día & 3 & 88 & 93 \\
\hline
\end{tabular}

trat aportan dos cibermedios y en ambos casos, saltan las fronteras territoriales para cubrir municipios del Maestrazgo de Teruel.

En l'Alcalatén, La veu de l'Alcalatén sirve desde l'Alcora la información a toda la comarca. En el Alto Palancia es Infopalancia el medio que da cobertura a los municipios de esta zona limítrofe con Teruel y Valencia. A ellos se suman los de Castellón capital: Castellón información y Castellón diario, ambos con una estructura informativa más próxima a la de los diarios en papel, cuyo modelo replican en internet.

En general los medios analizados mantienen una presentación formal de los temas agrupados por secciones, muy similares a las secciones de los diarios en papel.

Otro rasgo distintivo es el idioma empleado en los diarios (tabla 2). El catalán y el castellano, en un 40 y un $50 \%$ respectivamente, son los más utilizados en la redacción, en tanto que valenciano representa un $10 \%$.

Una característica destacada es la voluntad de interactuar con sus audiencias a través de las redes sociales para generar sinergias o retroalimentar sus informaciones. Todos incluyen en su página principal, salvo La veu de l'Alcalatén, una sección de participación y redes sociales: Twitter y Facebook. Sin embargo, en el período de seguimiento se detectó un bajo nivel de conversación, dado que los editores usan ambas plataformas para difundir, adaptándose a cada uno de los formatos, las noticias que incluyen en la web siguiendo la lógica de la autopromoción.

Es común a los medios estudiados una única actualización de su portada, salvo Castellón información que lo hace varias veces al día. La incorporación de noticias diarias a la portada varía (tabla 3). La mayoría de las informaciones responden al género de noticias y comparten espacio con la opinión de colaboradores políticos. Más del $80 \%$ de las informaciones de portada son notas de prensa de las administraciones, que se reproducen 
Tabla 4. Plantilla, presupuestos, fórmula de financiación y audiencia de los cibermedios

\begin{tabular}{|l|l|l|l|l|}
\hline \multicolumn{1}{|c|}{ Medio } & \multicolumn{1}{|c|}{ Plantilla } & \multicolumn{1}{c|}{ Presupuesto } & Financiación \\
\hline Castellón información & $\begin{array}{l}7 \text { periodistas } \\
1 \text { informático } \\
1 \text { administrativo } \\
\text { (todos autónomos) }\end{array}$ & 80.000 euros & Publicidad \\
\hline Comarques nord & 7 periodistas & 30.000 euros & Publicidad/Patrocinio \\
\hline Infopalancia & $\begin{array}{l}1 \text { redactor } \\
1 \text { fotógrafo } \\
10 \text { colaboradores }\end{array}$ & No facilita & $\begin{array}{l}\text { Publicidad institucional y comercial } \\
\text { venta de una app }\end{array}$ & 43.000 entradas/mes \\
\hline Infomaestrat & $\begin{array}{l}1 \text { redactor } \\
1 \text { informático }\end{array}$ & No facilita & Publicidad de las instituciones & No facilita \\
\hline Dia a dia & 3 redactores & No facilita & Publicidad institucional \\
\hline La veu de l'Alcaltén & $\begin{array}{l}1 \text { periodista/editor } \\
\text { colaborador }\end{array}$ & Recursos propios & Publicidad institucional \\
\hline
\end{tabular}

textualmente o con una mínima edición, el resto son de partidos políticos o entidades sociales. Se detecta una gran dependencia de las fuentes oficiales, lo que va en detrimento de la elaboración de contenidos propios, a partir de géneros como el reportaje o artículos de investigación, que les permitiría diferenciarse y captar lectores, aportando valor añadido a las noticias.

Una característica común es la falta de estudios previos de viabilidad y mercado

Excepciones a lo anterior son Infopalancia y Castellón información, con informaciones firmadas y un mínimo recurso a las notas oficiales, lo que se hace constar en el primer cibermedio, mientras que el segundo apuesta por la cobertura propia de la actividad institucional (Ayuntamiento y Diputación de Castellón).

Comarques nord introduce la posibilidad de visionar las informaciones en vídeos que incrustan en la portada. El medio aprovecha el material audiovisual que genera su canal de televisión, sacando más rendimiento al producto y empleando la web como herramienta multiplataforma. Sin embargo, ni este cibermedio ni el resto utilizan la hipertextualidad y sus informaciones carecen de enlaces a otras que ayuden a contextualizarlas.

Se echan en falta géneros como el periodismo de investigación o el reportaje, que requieren mayor especialización y recursos

\subsection{Fórmulas de financiación y plantillas}

La inversión precisa para crear estos medios (tabla 4) es uno de los problemas a los que se enfrentan los emprendedores periodísticos, de ahí que sea el propio periodista quien se embarque en un proyecto que se autofinancia y para el que utiliza su propio domicilio como redacción y su ordenador como herramienta de trabajo, además de la cámara fotográfica, la grabadora y el teléfono inteligente. Vito Palanques, editor de La veu de l'Alcalatén, afirma que su proyecto nació con un presupuesto de cero euros, sin estudio de mercado, y confiando en obtener publicidad institucional, respaldándose en 1.165.710 visitas acumuladas desde abril de 2011. Presupuesto "sin determinar" es el de Infomaestrat, que busca financiación en la publicidad institucional.

Tras "presupuesto sin determinar" se esconde la falta de recursos económicos externos, que se solventa con la aportación de las herramientas de trabajo necesarias, desde ordenadores y cámaras fotográficas hasta la oficina, como corroboran los editores de La veu de l'Alcalatén, Infopalancia o Infomaestrat. Caste-

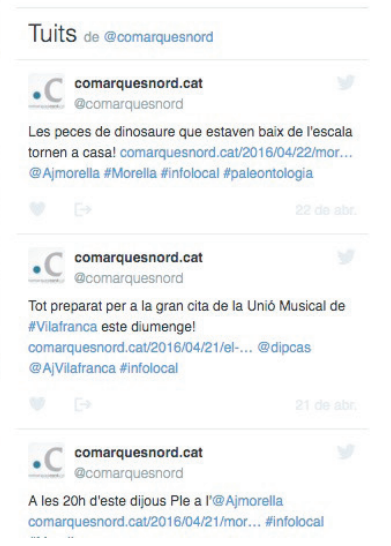

Inauguració de l'Espai de Lectura In contacontes, paradeta de libres,
A les 20h d'este dijous Ple a r@Aimorella 


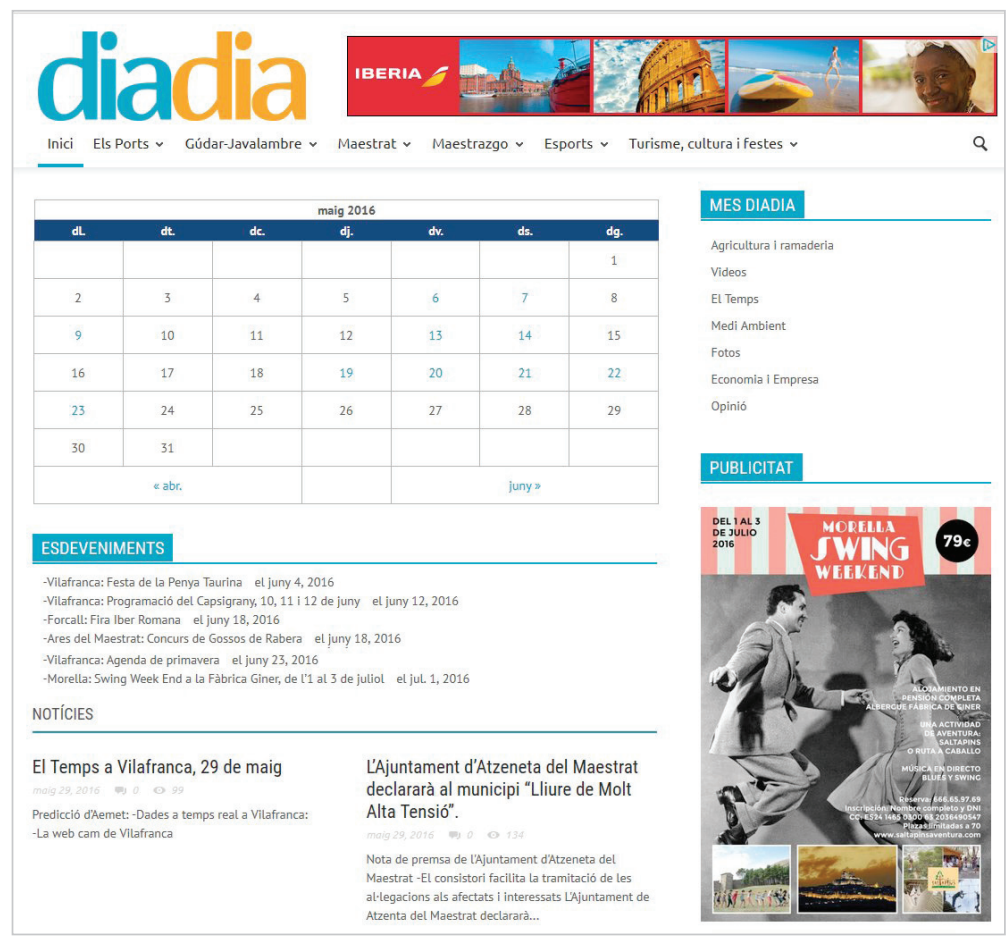

http://diadia.cat

Ilón información tiene oficina, aunque matiza que los redactores trabajan desde casa, mientras que los redactores de Comarques nord comparten las instalaciones de "la radio y televisión del grupo".

Castellón información y Comarques nord manejan presupuestos de 80.000 y 30.000 euros respectivamente, siendo la publicidad y los patrocinios institucionales sus fuentes de ingresos. Tan sólo Infopalancia añade a los ingresos publicitarios los procedentes de la venta de una app de informaciones culturales sobre la comarca.

Los otros cuatro medios no aportan datos de su volumen de negocio o del capital invertido para iniciar sus proyectos y responden con la aportación propia de medios técnicos y espacio físico del editor y fundador. Ello denota la opacidad y falta de transparencia de los nuevos diarios digitales, a pesar de que los de implantación estatal sí que muestran sus cuentas al público.

Una característica común es la falta de estudios previos de viabilidad y mercado, si bien Comarques nord hizo una estimación de mercado y un plan de desarrollo para garantizar la viabilidad del proyecto e Infopalancia también hizo estudios, aunque no los especifica. La veu de l'Alcalatén no estudió el mercado, pero valoró que la sociedad necesitaba conocer aquellas informaciones de su entorno sin cabida en los medios tradicionales. Esta es una necesidad que detectaron en Castellón información, donde además, "vimos que era una necesidad disponer de un medio online independiente donde trabajar de forma profesional", afirma su director Ximo Tirado. Con esa idea, y con la de dar empleo a los periodistas en paro, surgió el proyecto. Los editores de Dia a dia se embarcaron en el proyecto sin estudio previo, pero con la experiencia de 20 años de trabajo profesional en la comarca, "además, de haber participado en anteriores proyectos de diarios digitales, por lo que la empresa estaba creada", aclara el editor Lluís Puig.

A la vista de las respuestas a la encuesta se detecta la carencia de estudios de mercado, algo que conecta con la falta de tradición empresarial del periodista que ahora está en desigualdad con el editor tradicional. Eso genera dudas sobre la solidez del proyecto en la mayoría de los casos. Dudas que se suman a las derivadas de la dependencia, tanto informativa como publicitaria, de las administraciones de las que informan.

La estructura de las plantillas de estos cibermedios detecta nuevas fórmulas de relación laboral, como la de los autónomos que vincula a Castellón información con sus 7 redactores. Este medio también opta por la externalización de la gestión informática de la web y la administración.

Comarques nord emplea a 7 licenciados en comunicación audiovisual (uno coordina el ciberdiario), que también generan contenidos para la radio y televisión del grupo. Se encuadran en la figura del periodista multimedia.

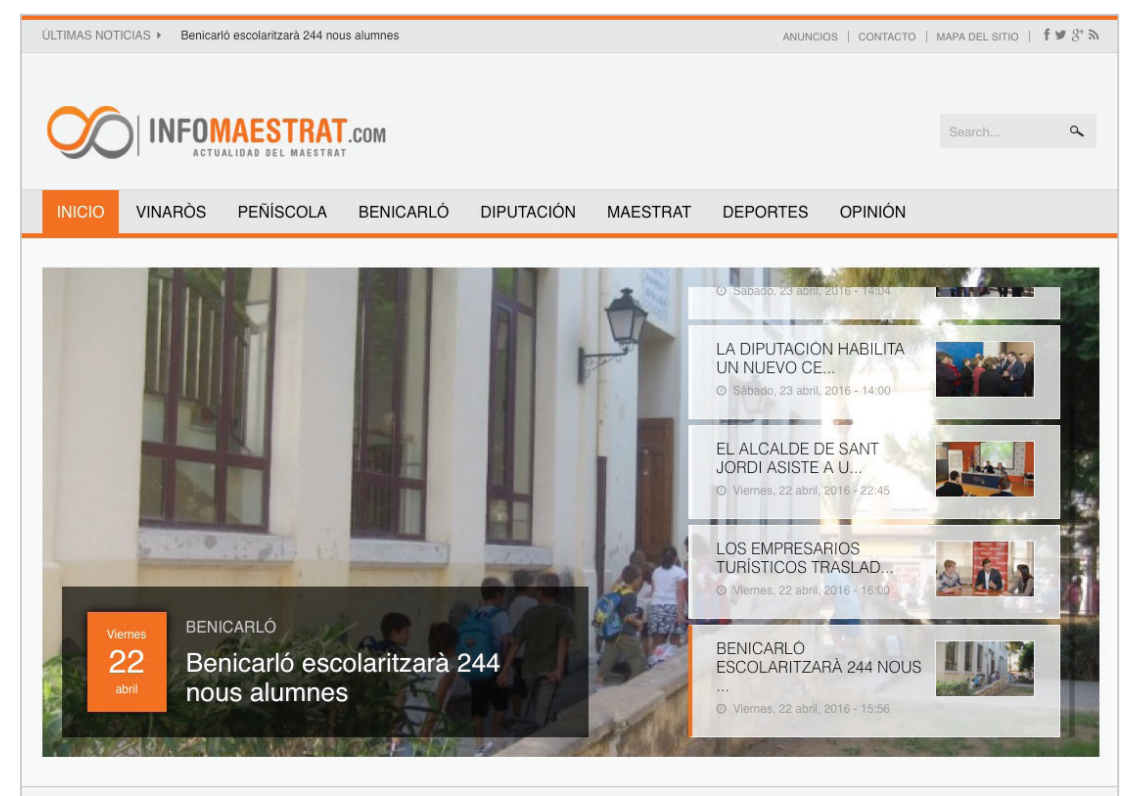

http://infomaestrat.com 


\section{Conclusiones}

La crisis económica ha generado cambios en el mercado periodístico castellonense, propiciando que los periodistas en paro apuesten por el emprendimiento creando sus medios online. Desde 2008 a julio de 2015, los periodistas en paro han creado 10 ciberdiarios que se suman a los 18 existentes. Del estudio se desprende que son profesionales con experiencia previa en medios locales y que han apostado por internet como soporte. Sólo en el caso de Comarques nord, el ciberdiario forma parte de un proyecto multimedia que engloba una emisora de radio y un canal de televisión.

Se trata de medios que buscan sobrevivir con ingresos publicitarios, mayoritariamente institucionales, patrocinios y en algunos casos, como Infopalancia y Comarques nord, con la venta de aplicaciones (app) y suscripciones, respectivamente. Ello denota que se han lanzado al mercado con criterios de empresa periodística tradicional, esperando cubrir los costes de producción y plantilla con los ingresos de la publicidad de las administraciones públicas: Diputación de Castellón o ayuntamientos, de cuya gestión informan y de las que reciben la mayor parte de las noticias que reproducen. $Y$ lo hacen sin disponer de equipos para buscar recursos económicos o publicitarios. Se echa en falta modelos que exploten las alternativas que ofrece internet a la financiación publicitaria tradicional. Esa doble dependencia de la Administración puede condicionar la supervivencia de estos medios y del fenómeno del periodismo digital local.

La economía precaria de los ciberdiarios condiciona sus plantillas de entre 1 y 7 personas (siempre con un redactor y un informático), salvo en los casos de Comarques nord o Castellón información que tienen 7 redactores. Además, no disponen de un plan de empresa sólido, algo que condiciona en gran medida su futuro y denota la carencia de formación empresarial de los periodistas, que se lanzan a competir en un mercado sin contar con las mismas herramientas de los empresarios tradicionales. Una situación que se agudiza más en el caso de los diarios digitales.

Más del $80 \%$ de las informaciones de portada son notas de prensa de las administraciones, que se reproducen textualmente o con una mínima edición

La investigación constata la existencia de nuevas figuras laborales en estos medios, como es el caso del autónomo (recurrentes en la prensa tradicional) que no se habían puesto de manifiesto tan claramente, por lo que este trabajo lo refuerza. El ámbito de actuación es hiperlocal, comarcal, aunque algunos cubran las comarcas limítrofes.

Una peculiaridad es el recurso de los nuevos medios al empleo como lengua vehicular de la que utilizan los lectores de la zona en que radican en busca de reforzar el carácter vertebrador del idioma para generar empatía en los consumidores. Así, en este territorio los medios no dudan usar el catalán (40\%) en las zonas limítrofes con Catalunya, aunque el castellano (50\%) pese más a la hora de dirigirse a los públicos objetivos de los diarios digitales, quedando reducido el uso del valenciano a un casi testimonial $10 \%$.

El principal recurso informativo de estos diarios son las noticias de procedencia institucional, lo que permite a los gabinetes de comunicación controlar mejor el contenido del mensaje que llega a las audiencias. Se echan en falta géneros más elaborados como el periodismo de investigación o el reportaje, que requieren mayor especialización y recursos.

Los ciberdiarios analizados para este trabajo desaprovechan una buena parte de los recursos tecnológicos que les proporciona la Red, dado que no utilizan la hipertextualidad y la multimedialidad para enriquecer y contextualizar las informaciones que ofrecen. Tan sólo Comarques nord incorpora vídeos que complementan algunas de sus noticias.

En síntesis, este artículo detecta dos limitaciones importantes en los cibermedios creados por los periodistas

- falta de estudios previos de mercado, y

- fuerte dependencia informativa y de financiación de las instituciones oficiales, que ya se está detectando en los últimos tiempos en la prensa tradicional. Sin embargo, es un fenómeno que se agudiza más en los digitales por la escasez de recursos con los que cuentan.

Los ciberdiarios analizados desaprovechan una buena parte de los recursos tecnológicos de la Red, ya que no utilizan la hipertextualidad y la multimedialidad

\section{Nota}

1. Los medios y sus editores diferencian entre catalán y valenciano en base a las normas de la Academia Valenciana de la Lengua.

\section{Bibliografía}

Asociación de la Prensa de Madrid (2014). Informe anual la profesión periodística. Madrid: APM.

http://www.apmadrid.es/publicaciones/informe-anual-dela-profesión-periodistica

Albarrán, Alan B. (2010). The media economy. New York: Routledge. ISBN: 9780415990462

Balcells, Josep (1994). La investigación social. Introducción a los métodos y las técnicas. Barcelona: SA PPU. ISBN: 978 8447703791

Bruno, Nicola; Nielsen, Rasmus-Kleis (2012). Survival is success: Journalistic online start-ups in Western Europe. University of Oxford: Reuters Institute for the Study of Journalism (RISJ). ISBN: 9781907384080

https://goo.gl/seMdmL

Casero-Ripollés, Andreu (2010). "Prensa en internet: nuevos modelos de negocio en el escenario de la convergencia". El profesional de la información, v. 19, n. 6, pp. 595-601. http://recyt.fecyt.es/index.php/EPI/article/view/epi.2010. nov.05

http://dx.doi.org/10.3145/epi.2010.nov05 
Casero-Ripollés, Andreu (2012a). “La reconversión del periodismo: nuevos modelos de negocio en el panorama digital. En: Salgado-García, Fernando; Martínez, ValentínAlejandro (ed.). Economía de la cultura y la comunicación en la era digital, pp. 353-377. Lisboa: Media XXI. ISBN: 978 9897290282

Casero-Ripollés, Andreu (2012b). “Más allá de los diarios: el consumo de noticias de los jóvenes en la era digital". Comunicar, v. 20, n. 39, pp. 151-158.

http://dx.doi.org/10.3916/C39-2012-03-05

Casero-Ripollés, Andreu; Cullell-March, Cristina (2013). "Periodismo emprendedor. Estrategias para incentivar el autoempleo periodístico como modelo de negocio". Estudios sobre el mensaje periodístico, n. 19, pp. 681-690. http://dx.doi.org/10.5209/rev_ESMP.2013.v19.42151

Casero-Ripollés, Andreu; Izquierdo-Castillo, Jessica (2013). "Between decline and a new online business model: the case of the Spanish newspaper industry". Journal of media business studies, n. 10.

http://dx.doi.org/10.1080/16522354.2013.11073560

Castells, Manuel (2001). La galaxia internet. Barcelona: Plaza y Janés Editores. ISBN: 9788401341571

Curran, James (2010). "The future of journalism". Journalism studies, v. 11, n. 4, pp. 464-476.

http://dx.doi.org/10.1080/14616701003722444

De-Fontcuberta, Mar (1997). "La identidad regional de los medios". Cuadernos de información, n. 12, pp. 45-50. https://dialnet.unirioja.es/servlet/articulo?codigo $=2939041$

Díaz-Nosty, Bernardo (2013). La prensa en el nuevo ecosistema informativo. iQue paren las rotativas! Barcelona: Ariel/Fundación Telefónica. ISBN: 9788408112969 http://boletines.prisadigital.com/la_prensa_en_el_nuevo_ ecosistema_informativo.pdf

Faustino, Paulo; Gonçalez, Ramiro (2011). Gestão estratégica e modelos de negócio. O caso da indústria de mídia. Lisboa: Media XXI/Formalpress. ISBN: 9789898143747

García-Santamaría, José-Vicente (ed.) (2014). El negocio de la prensa digital. En busca de un modelo sostenible para los nuevos tiempos. Logroño: Publicaciones de la Universidad Internacional de La Rioja. ISBN: 9788416125258

Gil, Quim (2004). "Análisis centrípeto de la periodista en red. Nuevos perfiles profesionales". Telos, n. 59, abril-junio. http://telos.fundaciontelefonica.com/telos/articulocuaderno. asp@idarticulo=2\&rev=59.htm

Giles, Robert H. (2010). "New economic models for U.S. journalism". Dedalus, v. 139, n. 2, pp. 26-38. http://dx.doi.org/10.1162/daed.2010.139.2.26

Herbert, Jack; Thurman, Neil (2007). "Paid content strategies for news websites". Journalism practice, v. 1, n. 2, pp. 208-226. http://openaccess.city.ac.uk/118/

http://dx.doi.org/10.1080/17512780701275523

Larrañaga-Rubio, Julio (2009). "La crisis del modelo económico de la industria de los periódicos". Estudios sobre el mensaje periodístico, n. 15, pp. 61-80. http://revistas.ucm.es/index.php/ESMP/article/view/ ESMP0909110061A

López-García, Guillermo (2006). "Los cibermedios valencianos: orígenes, evaluación y balance de conjunto". En: LópezGarcía, Guillermo (ed.). Comunicación local y nuevos formatos periodísticos en internet: cibermedios, confidenciales $y$ weblogs, pp. 71-81. ISBN: 9788469168189 http://www.cibermediosvalencianos.es/comloc/Lopez.pdf

Manfredi-Sánchez, Juan-Luis; Torrijos-Rojas, José-Luis; Herranz-de-la-Casa, José-María (2015). “Innovación en el periodismo emprendedor deportivo. Modelo de negocio y narrativas". El profesional de la información, v. 24, n. 3, pp. 265-273.

http://dx.doi.org/10.3145/epi.2015.may.06

Pérez-Bahón, Félix; Clemente, Dolores (2014) “La tecnología". En: García-Santamaría, José-Vicente (ed.). El negocio de la prensa digital. En busca de un modelo sostenible para los nuevos tiempos. Logroño: Publicaciones de la Universidad Internacional de La Rioja. ISBN: 9788416125258

Piccard, Robert G. (2004): “Commercialism and newspaper quality". Newspaper research journal, n. 25, pp. 54-65. http://dx.doi.org/10.1177/073953290402500105

Rom, Josep; Masip, Pere (eds.) (2005). La utopia digital en els mitjans de comunicació: dels discursos als fets. Un balanç. Trípodos extra. III Congrés internacional comunicació $i$ realitat.

Rosenstiel, Tom; Jurkowitz, Mark; Ji, Hong (2012). "The search for a new business model: How newspapers are faring trying to build digital revenue". Journalism \& media, March 5. Pew Research Center.

http://www.journalism.org/analysis_report/search_new_ business_model

Salaverría, Ramón; Cores, Rafael; Díaz-Noci, Javier; Meso, Koldo; Larrondo, Ainara (2004). "Evaluación de los ciberdiarios en las comunidades vasca y navarra". Comunicación y sociedad, n. 17, pp. 161-192.

http://hdl.handle.net/10171/5069

Salaverría, Ramón; Negredo, Samuel (2008). Periodismo integrado. Convergencia de medios y reorganización de redacciones. Barcelona: Sol90. ISBN: 9788498209549

Toffler, Alvin (1980). La tercera ola. Barcelona: Plaza y Janes. ISBN: 8401370663

Vizcaíno-Laorga-Gavilán, Ricardo (2006). "Prensa gallega en Internet: análisis del diseño y los servicios". En: Ledo-Andión, Margarita (coord.). Comunicación local: da pesquisa á producción. Actas do Congreso Internacional Lusocom. Santiago de Compostela, 21-22 abril. Universidad de Santiago de Compostela, Servicio de Publicaciones, pp. 4.923-4.936. ISBN: 8497506200

Yuste, Bárbara; Cabrera, Margarita (2014). Emprender en periodismo. Nuevas oportunidades para el profesional de la información. Barcelona: Editorial UOC. ISBN: 978849064 0708 